\title{
Cancer predisposition syndromes as a risk factor for early second primary neoplasms after childhood cancer - A national cohort study
}

\author{
Nicolas Waespe ${ }^{\text {a,b }}$, Fabiën N. Belle ${ }^{\text {a,c }}$, Shelagh Redmond ${ }^{\mathrm{a}}$, \\ Christina Schindera ${ }^{\mathrm{a}, \mathrm{d}}$, Ben D. Spycher ${ }^{\mathrm{a}}$, Jochen Rössler ${ }^{\mathrm{e}}$, \\ Marc Ansari ${ }^{\text {b,f }}$, Claudia E. Kuehni ${ }^{\mathrm{a}, \mathrm{e}, *}$, for the Swiss Paediatric Oncology \\ Group (SPOG)
}

\footnotetext{
a Institute of Social and Preventive Medicine, University of Bern, Switzerland

${ }^{\mathrm{b}}$ Research Platform for Pediatric Oncology and Hematology (CANSEARCH Research Platform), Department of Pediatrics, Gynecology, and Obstetrics, University of Geneva, Switzerland

${ }^{\mathrm{c}}$ Centre universitaire de médecine générale et santé publique (UNISANTÉ), Institute of Social and Preventive Medicine (IUMSP), University of Lausanne, Switzerland

${ }^{\mathrm{d}}$ Division of Pediatric Oncology/ Hematology, University Children's Hospital Basel, University of Basel, Switzerland

${ }^{\mathrm{e}}$ Division of Pediatric Hematology and Oncology, University Children's Hospital Bern, Switzerland

${ }^{\mathrm{f}}$ Department of Pediatrics, Pediatric Oncology and Hematology Unit, Geneva University Hospitals, Geneva, Switzerland
}

Received 17 August 2020; received in revised form 17 October 2020; accepted 23 November 2020

\author{
KEYWORDS \\ Neoplasms; \\ Second primary \\ neoplasms; \\ Hereditary neoplastic \\ syndromes; \\ Cancer survivors; \\ Swiss childhood cancer \\ registry;
}

\begin{abstract}
Background: Childhood cancer patients are at increased risk of second primary neoplasms (SPNs). We assessed incidence and risk factors for early SPNs with a focus on cancer predisposition syndromes (CPSs).

Patients and methods: This cohort study used data from the Swiss Childhood Cancer Registry. We included patients with first primary neoplasms (FPNs) diagnosed before age 21 years from 1986 to 2015 and identified SPNs occurring before age 21. We calculated standardised incidence ratios (SIRs) and absolute excess risks (AERs) using Swiss population cancer incidence data, and cumulative incidence of SPNs. We calculated hazard ratios (HRs) of risk factors for SPNs using Fine and Gray competing risk regression.
\end{abstract}

Abbreviations: AER, Absolute excess risk; CI, 95\% confidence interval; CNS, central nervous system; CPS, cancer predisposition syndrome; FPN, first primary neoplasm; HR, hazard ratio; HSCT, haematopoietic stem cell transplantation; IARC, International Agency for Research on Cancer; ICCC-3, International Classification of Childhood Cancer, third edition; IQR, interquartile range; PY, person-years; SIR, standardised incidence ratio; SPN, second primary neoplasm; SCCR, Swiss Childhood Cancer Registry; SPOG, Swiss Paediatric Oncology Group.

* Corresponding author: Institute of Social and Preventive Medicine, University of Bern, Mittelstrasse 43, 3012, Bern, Switzerland

E-mail address: claudia.kuehni@ispm.unibe.ch (C.E. Kuehni). 
Early detection of cancer;

Genetic counselling; Genetic testing;

Pediatrics;

Adolescent medicine
Results: Among 8074 childhood cancer patients, 304 (4\%) were diagnosed with a CPS and 94 $(1 \%)$ developed early SPNs. The incidence of SPNs was more than 10-fold higher in childhood cancer patients than the incidence of neoplasms in the general population ( $\mathrm{SIR}=10.6,95 \%$ confidence interval [CI]: 8.7-13.1) and the AER was 179/100,000 person-years (CI: 139-219). Cumulative incidence of SPNs 20 years after FPN diagnosis was 23\% in patients with CPSs (CI: $12-41 \%$ ) and $2.7 \%$ in those without (CI: $2.0-3.6 \%$ ). Risk factors for SPNs were CPSs $(\mathrm{HR}=7.8, \mathrm{CI}: 4.8-12.7)$, chemotherapy $(\mathrm{HR}=2.2, \mathrm{CI}: 1.1-4.6)$, radiotherapy $(\mathrm{HR}=$ $1.9, \mathrm{CI}=1.2-2.9)$, haematopoietic stem cell transplantation $(\mathrm{HR}=1.8, \mathrm{CI}: 1-3.3)$, and older age (15-20 years) at FPN diagnosis (HR $=1.9, \mathrm{CI}: 1.1-3.2)$.

Conclusion: CPSs are associated with a high risk of SPNs before age 21 years. Identification of CPSs is important for appropriate cancer surveillance and targeted screening.

(C) 2020 The Author(s). Published by Elsevier Ltd. This is an open access article under the CC BY-NC-ND license (http://creativecommons.org/licenses/by-nc-nd/4.0/).

\section{Introduction}

While most children can be cured of their first primary neoplasm (FPN) with modern treatments, they remain at risk of second primary neoplasms (SPNs) throughout their life. SPNs are an important cause of morbidity and the most common cause of death in long-term childhood cancer survivors after recurrence of FPNs [1-5]. Early SPNs, defined here as occurring before 21 years of age, have been mostly studied together with SPNs occurring later in life. From many studies, early SPNs were excluded because the analysis had been restricted to adult survivors [2,6-10]. The standardised incidence ratio of SPNs in cancer patients compared with neoplasms in the general population is highest during childhood and adolescence [11-13]. Overall survival of patients with SPNs is low and poorest in SPNs occurring within the first five years after FPN [4]. Risk factors for early SPNs have only been assessed in one previous study which showed radiotherapy and chemotherapy to be associated with SPNs [4].

Cancer predisposition syndromes (CPSs) are genetic conditions associated with an increased risk of development of neoplasms [14-16]. More than 40 different CPSs have been associated with a wide range of neoplasms during childhood and adolescence [17]. So far, there are no studies that assessed CPSs as possible risk factor for early SPNs on a population-based level. Our study aimed to describe the incidence of SPNs in Swiss childhood cancer patients occurring before 21 years of age, identify CPSs associated with early SPNs, and assess potential risk factors for SPNs with a special focus on CPSs.

\section{Patients and methods}

\subsection{Study design, study population and inclusion criteria}

We performed a cohort study based on the Swiss Childhood Cancer Registry (SCCR). The SCCR collects data on all children and adolescents diagnosed with a neoplasm including leukaemias, lymphomas, central nervous system tumours, and malignant solid tumours under the age of 21 years since 1976 in Switzerland [18]. For this analysis, we restricted the diagnosis period to 1986-2015 which has a high completeness of registration [19]. We included all neoplasms fulfilling criteria for the 12 main groups of the International Classification of Childhood Cancer, third edition (ICCC-3) [20], and excluded patients with nonmelanoma skin cancer because of incomplete reporting. The Ethics Committee of the Canton of Bern gave its approval to the SCCR (KEK-BE 166/2014).

\subsection{Demographic, cancer and treatment characteristics}

We extracted demographic, cancer and treatment characteristics for all childhood cancer patients with an FPN from the SCCR. This included information on sex, age at diagnosis, year of diagnosis, diagnosis classified into 12 main groups of the ICCC-3 [20], relapse, underlying diseases, treatments, and survival. Treatment was categorised into binary variables indicating exposure to chemotherapy, radiotherapy and haematopoietic stem cell transplantation (HSCT).

\subsection{Cancer predisposition syndromes}

We collected and reviewed medical records from patients for whom underlying diseases were reported to the SCCR database (Supplementary Text A1). Yearly follow-up information was continuously reported to the SCCR from hospitals involved in childhood cancer care. We classified underlying diseases as CPSs if they were reported in the current literature to be associated with an increased relative risk of neoplasms compared with the general population [21].

\subsection{Identification and ascertainment of second primary neoplasms}

We identified SPNs using the SCCR (Supplementary Text A2) [22]. We included all SPNs that occurred before age 21 years. We verified all SPNs with the 
Table 1

Demographic, cancer and treatment characteristics of 8074 Swiss childhood cancer patients diagnosed with a first primary neoplasm between 1986 and 2015, overall and stratified by diagnosis of second primary neoplasm.

\begin{tabular}{|c|c|c|c|}
\hline \multirow[t]{2}{*}{ Characteristics } & \multirow[t]{2}{*}{ Total $(\mathrm{n}, \%)$} & \multicolumn{2}{|c|}{ Second primary neoplasms } \\
\hline & & No $(n, \%)$ & Yes $(\mathrm{n}, \%)$ \\
\hline \multicolumn{4}{|l|}{$\overline{\operatorname{Sex}}$} \\
\hline Female & $3582(45)$ & $3544(44)$ & $38(40)$ \\
\hline Male & $4492(56)$ & $4436(56)$ & $56(60)$ \\
\hline \multicolumn{4}{|l|}{ Age at diagnosis of first primary neoplasm } \\
\hline Median (years, IQR) & $10.6(4.0-16.5)$ & $10.7(4.0-16.5)$ & $6.8(2.6-14.2)$ \\
\hline $0-4$ & $2431(30)$ & $2390(30)$ & $41(44)$ \\
\hline $5-9$ & $1435(18)$ & $1415(18)$ & $20(21)$ \\
\hline $10-14$ & $1615(20)$ & $1604(20)$ & $11(12)$ \\
\hline $15-20$ & $2593(32)$ & $2571(32)$ & $22(23)$ \\
\hline \multicolumn{4}{|l|}{ Diagnosis of first primary neoplasm } \\
\hline 1986-1995 & $2409(30)$ & $2382(30)$ & $27(29)$ \\
\hline 1996-2005 & $2703(34)$ & $2662(33)$ & $41(44)$ \\
\hline $2006-2015$ & $2962(37)$ & $2936(37)$ & $26(28)$ \\
\hline \multicolumn{4}{|l|}{ Diagnostic group of first primary neoplasm (ICCC-3) } \\
\hline Leukaemia, myeloproliferative and myelodysplastic diseases & $2067(26)$ & $2038(26)$ & $29(31)$ \\
\hline Lymphomas and reticuloendothelial neoplasms & $1280(16)$ & $1267(16)$ & $13(14)$ \\
\hline CNS and miscellaneous intracranial and intraspinal neoplasms & $1578(20)$ & $1562(20)$ & $16(17)$ \\
\hline Neuroblastoma and other peripheral nervous cell tumours & $386(5)$ & $380(5)$ & $6(6)$ \\
\hline Retinoblastoma & $140(2)$ & $136(2)$ & $4(4)$ \\
\hline Renal tumours & $305(4)$ & $301(4)$ & $4(4)$ \\
\hline Hepatic tumours & $85(1)$ & $82(1)$ & $3(3)$ \\
\hline Malignant bone tumours & $419(5)$ & $414(5)$ & $5(5)$ \\
\hline Soft-tissue and other extraosseous sarcomas & $556(7)$ & $549(7)$ & $7(7)$ \\
\hline $\begin{array}{l}\text { Germ-cell tumours, trophoblastic tumours, and } \\
\text { neoplasms of gonads }\end{array}$ & $498(6)$ & $492(6)$ & $6(6)$ \\
\hline $\begin{array}{l}\text { Other malignant epithelial neoplasms and malignant } \\
\text { melanomas }\end{array}$ & $711(9)$ & $710(9)$ & $1(1)$ \\
\hline Other and unspecified malignant neoplasms & $49(1)$ & $49(1)$ & $0(0)$ \\
\hline \multicolumn{4}{|l|}{ Relapse after first primary neoplasm } \\
\hline Yes & $1473(18)$ & $1451(18)$ & $22(23)$ \\
\hline No & $6601(82)$ & $6529(82)$ & $72(77)$ \\
\hline \multicolumn{4}{|l|}{ Cancer predisposition syndromes } \\
\hline Yes & $304(4)$ & $283(4)$ & $21(22)$ \\
\hline No & $7770(97)$ & $7697(96)$ & $73(78)$ \\
\hline \multicolumn{4}{|l|}{ Treatment of first primary neoplasm } \\
\hline \multicolumn{4}{|l|}{ Chemotherapy } \\
\hline Yes & $5667(70)$ & $5583(70)$ & $84(89)$ \\
\hline No & $1551(19)$ & $1543(19)$ & $8(9)$ \\
\hline Missing & $856(11)$ & $854(11)$ & $2(2)$ \\
\hline \multicolumn{4}{|l|}{ Radiotherapy } \\
\hline Yes & $2293(28)$ & $2248(28)$ & $45(48)$ \\
\hline No & $4800(60)$ & $4753(60)$ & $47(50)$ \\
\hline Missing & $981(12)$ & $979(12)$ & $2(2)$ \\
\hline \multicolumn{4}{|l|}{ Haematopoietic stem cell transplantation } \\
\hline Yes & $653(8)$ & $638(8)$ & $15(16)$ \\
\hline No & $6356(79)$ & $6279(79)$ & $77(82)$ \\
\hline Missing & $1065(13)$ & $1063(13)$ & $2(2)$ \\
\hline \multicolumn{4}{|l|}{ Survival up to 21 years of age } \\
\hline Alive & $6378(79)$ & $6318(79)$ & $60(64)$ \\
\hline Dead & $1696(21)$ & $1662(21)$ & $34(36)$ \\
\hline
\end{tabular}

Abbreviations: CNS, central nervous system; ICCC-3, international classification of childhood cancer, third edition; IQR, interquartile range; $n$, number.

original data source (pathology reports, medical records, cantonal cancer registry and SCCR notification forms, or death certificates) and coded them as per the International Agency for Research on Cancer (IARC) criteria for SPN coding [23]. In brief, we included SPNs that were included in the ICCC-3 classification, were originated in different tissues, or had a different morphology than the FPN and were not non-melanoma skin cancer, or progression, transformation, metastasis, and relapse of the FPN. 


\subsection{Statistical analysis}

We defined time at risk as the time from date of diagnosis of the FPN until occurrence of the first SPN or (i) last date of hospital follow-up, (ii) last contact with the SCCR (e.g. survivor questionnaire reply), or (iii) date of last vital status from cantonal cancer registries, whichever occurred last before 21 years of age. We censored all follow-up information after December $31^{\text {st }}, 2015$, the end of our observation period. To assess mortality, we used data from the SCCR which performs regular updates of survival status in its cohort with the Swiss national death registry.

We stratified observed SPNs by sex, ICCC-3 diagnostic group, age at diagnosis in 5-year groups, and 10-year calendar period of diagnosis. As reference for expected neoplasms, we used incidence rates from the SCCR for ages 0-14 years and from the Swiss Federal Office of Health for the Swiss population for ages 15-20 years $[24,25]$ and multiplied the incidence rate by the observation time for each stratum. We calculated standardised incidence ratios (SIRs) by dividing observed numbers of SPNs in childhood cancer patients by expected numbers in the general population (indirect standardisation). We calculated the absolute excess risk (AER) per 100,000 person-years (py) by subtracting the expected number of FPNs from the observed number of SPNs, dividing by observation time at risk in py, and multiplying by 100,000.

We used competing risk regression models as described by Fine and Gray [26] to estimate hazard ratios (HRs) for predefined possible risk factors with death as a competing risk to the main outcome. For missing treatment information, we performed multiple imputation by chained equations (Supplementary Text A3). We then performed univariable competing risk regressions for having an SPN with the following potential risk factors: sex, age at FPN diagnosis, year of FPN diagnosis, diagnostic group of FPN (according to ICCC-3), relapse of FPN, underlying CPSs, and treatment characteristics (chemotherapy, radiotherapy, HSCT as binary variables). We performed a multivariable competing risk regression including sex, and all characteristics associated in the univariable models with a two-sided $\mathrm{p}$-value of $\leq 0.1$. As a sensitivity analysis, we also performed all regression analyses using complete cases only. We plotted the cumulative incidence of SPNs over time since FPN diagnosis with death as a competing risk and stratified patients by presence of CPSs. We used STATA software for statistical analysis (Version 15.1, Stata Corporation, Austin, TX).

Table 2

Clinical characteristics of 96 second primary neoplasms in 94 patients, overall and stratified by diagnosis of cancer predisposition syndrome.

\begin{tabular}{|c|c|c|c|}
\hline \multirow[t]{2}{*}{ Characteristics } & \multirow[t]{2}{*}{ Total $(\mathrm{n}, \%)$} & \multicolumn{2}{|c|}{ Cancer predisposition syndromes } \\
\hline & & No $(n, \%)$ & Yes $(n, \%)$ \\
\hline \multicolumn{4}{|l|}{ Diagnostic group of second primary neoplasm (ICCC-3) ${ }^{b}$} \\
\hline Leukaemias, myeloproliferative and myelodysplastic diseases & $18(19)$ & $16(22)$ & $2(9)$ \\
\hline Lymphomas and reticuloendothelial neoplasms & $10(10)$ & $9(12)$ & $1(5)$ \\
\hline CNS and miscellaneous intracranial and intraspinal neoplasms & $20(21)$ & $12(16)$ & $8(36)$ \\
\hline Neuroblastoma and other peripheral nervous cell tumours & $3(3)$ & $1(1)$ & $2(9)$ \\
\hline Retinoblastoma & $0(0)$ & $0(0)$ & $0(0)$ \\
\hline Renal tumours & $5(5)$ & $2(3)$ & $3(14)$ \\
\hline Hepatic tumours & $0(0)$ & $0(0)$ & $0(0)$ \\
\hline Malignant bone tumours & $8(8)$ & $5(7)$ & $3(14)$ \\
\hline Soft-tissue and other extraosseous sarcomas & $9(9)$ & $7(9)$ & $2(9)$ \\
\hline Germ-cell tumours, trophoblastic tumours, and neoplasms of gonads & $5(5)$ & $4(5)$ & $1(5)$ \\
\hline Other malignant epithelial neoplasms and malignant melanomas ${ }^{\mathrm{a}}$ & $18(19)$ & $18(24)$ & $0(0)$ \\
\hline Other and unspecified malignant neoplasms & $0(0)$ & $0(0)$ & $0(0)$ \\
\hline \multicolumn{4}{|l|}{ Time from first primary to second primary neoplasm } \\
\hline Median (years, IQR) & $4.6(2.7-8.4)$ & $4.9(2.7-8.4)$ & $4.0(2.7-8.3)$ \\
\hline \multicolumn{4}{|l|}{ Age at diagnosis of second primary neoplasm ${ }^{\mathrm{b}}$} \\
\hline Median (years, IQR) & $14.8(9.8-17.7)$ & $15.0(9.9-17.7)$ & $13.6(7.5-17.3)$ \\
\hline $0-4$ years & $6(6)$ & $3(4)$ & $3(14)$ \\
\hline $5-9$ years & $20(21)$ & $17(23)$ & $3(14)$ \\
\hline $10-14$ years & $24(25)$ & $17(23)$ & $7(32)$ \\
\hline $15-20$ years & $46(48)$ & $37(50)$ & $9(41)$ \\
\hline \multicolumn{4}{|l|}{ Year of diagnosis of second primary neoplasm ${ }^{b}$} \\
\hline $1986-1995^{\circ}$ & $8(8)$ & $8(11)$ & $0(0)$ \\
\hline $1996-2005$ & $32(33)$ & $29(39)$ & $3(14)$ \\
\hline $2006-2015$ & $56(58)$ & $37(50)$ & $19(86)$ \\
\hline
\end{tabular}

Abbreviations: CNS, central nervous system; ICCC-3, international classification of childhood cancer, third edition; IQR, interquartile range; $\mathrm{n}$, number.

${ }^{a}$ Other epithelial neoplasms that were identified in this group: thyroid carcinomas, $\mathrm{n}=10$; malignant melanomas, $\mathrm{n}=4$; mucoepidermoid carcinomas of the parotid gland, $\mathrm{n}=3$; adenocarcinoma of the bile ducts, $\mathrm{n}=1$.

${ }^{\mathrm{b}}$ Including multiple SPNs occurring in two patients. 


\section{Results}

\subsection{Cohort characteristics}

We included 8074 patients in our study (Supplementary Figure A4). Cumulative follow-up time was 47,464 py and median attained age at last follow-up was 18.8 years (interquartile range [IQR]: 13.1-20.9). Among included patients, 92 patients were diagnosed with one SPN and two patients with two SPNs during follow-up. Median age at FPN diagnosis was 6.8 years (IQR: 2.6-14.2) for patients with an SPN and 10.7 years (IQR: $4.0-16.5$ ) for those without (Table 1). SPNs occurred mainly after leukaemias $(\mathrm{n}=29,31 \%)$, central nervous system (CNS) neoplasms ( $\mathrm{n}=16,17 \%)$, and lymphomas ( $\mathrm{n}=13,14 \%$ ), which represent also the most common FPNs in this age range. A higher proportion of patients who later developed SPNs had undergone treatment with chemotherapy, radiotherapy, or HSCT for their FPN compared with those who did not develop an SPN. Relapse after FPN was seen in $23 \%(n=22)$ in those with and $18 \%(\mathrm{n}=1451)$ in those without SPNs. Overall survival up to 21 years of age was lower in patients with SPNs $(64 \%)$ than in those without $(79 \%)$.

\subsection{Cancer predisposition syndromes}

We identified 304 (4\%) childhood cancer patients with a CPS (Supplementary Table A5). The most common CPSs were neurofibromatosis types I and II $(\mathrm{n}=89$, $29 \%$ of patients with CPSs), trisomy 21 and mosaic trisomies $(\mathrm{n}=73,24 \%)$, and familial/bilateral retinoblastoma ( $\mathrm{n}=45,15 \%)$. In total, 27 different CPSs were identified, of which the majority $(\mathrm{n}=20,74 \%)$ was seen in five or less patients each. Patients diagnosed with their FPN in more recent years were slightly more often identified with a CPS $(3.1 \%$ in the period $1986-95,4.0 \%$ in 1996-2005, and 4.1\% in 2006-2015; $\mathrm{p}$ for trend 0.08). Twenty-one of 304 patients with CPSs (7\%) developed an early SPN under age 21 . Of those, only one patient $(5 \%)$ with mismatch repair syndrome was identified after diagnosis of the SPN.

\subsection{Second primary neoplasms}

SPNs were seen within the first month up to 16.8 years after FPN diagnosis (Table 2). Median time from diagnosis of FPN to SPN was 4.0 and 4.9 years, and median age at SPN was 13.6 and 15 years in those with and without CPSs, respectively. The most common SPNs were CNS neoplasms $(\mathrm{n}=20)$, leukaemias and myelodysplastic diseases $(n=18)$, malignant epithelial neoplasms and malignant melanomas $(\mathrm{n}=18)$. We cross-tabulated FPNs with SPNs and found that first primary leukaemias and myelodysplastic diseases were commonly associated with second primary malignant epithelial neoplasms $(\mathrm{n}=8)$ and with lymphomas $(\mathrm{n}=7)$, lymphomas with malignant epithelial neoplasms $(\mathrm{n}=7)$, and CNS tumours with subsequent CNS neoplasms $(\mathrm{n}=6)$ (Supplementary Table A6).

\subsection{Standardised incidence ratios and absolute excess risks}

The risk of having an SPN in childhood cancer patients was more than 10-fold higher than the risk of having a neoplasm in the general population (SIR $=10.6 ; 95 \%$ CI: 8.7-13.1) (Table 3). We found the highest risk ratios for renal tumours (SIR $=24.4,95 \% \mathrm{CI}$ : 10.2-58.6), soft-tissue sarcomas $(\mathrm{SIR}=18.5,95 \%$ CI 9.6-35.6),

Table 3

Standardised incidence ratios and absolute excess risks of second primary neoplasms in childhood cancer patients in relation to the general population stratified by ICCC-3 classification.

\begin{tabular}{|c|c|c|c|c|}
\hline Diagnostic group of second primary neoplasm (ICCC-3) & $\begin{array}{l}\text { Observed } \\
\text { (n) }\end{array}$ & $\begin{array}{l}\text { Expected } \\
\text { (n) }\end{array}$ & $\begin{array}{l}\text { SIR } \\
\text { (CI) }\end{array}$ & $\begin{array}{l}\text { AER } \\
\text { (CI; per 100,000 } \\
\text { person-years) }\end{array}$ \\
\hline Leukaemias, myeloproliferative and myelodysplastic diseases & 16 & 1.8 & $9.1(5.6-14.9)$ & $30.0(13.5-46.5)$ \\
\hline Lymphomas and reticuloendothelial neoplasms & 10 & 1.9 & $5.3(2.9-9.9)$ & $17.1(4.1-30.2)$ \\
\hline CNS and miscellaneous intracranial and intraspinal neoplasms & 20 & 1.4 & $14.8(9.6-22.9)$ & $39.0(20.8-57.8)$ \\
\hline Neuroblastoma and other peripheral nervous cell tumours & 3 & 0.2 & $16.8(5.4-52.1)$ & $5.9(-1.2-13.1)$ \\
\hline Retinoblastoma & 0 & 0.1 & 0 & $-0.2(-)$ \\
\hline Renal tumours & 5 & 0.2 & $\begin{array}{l}24.4(10.2 \\
-58.6)\end{array}$ & $10.1(0.9-19.4)$ \\
\hline Hepatic tumours & 0 & 0.1 & 0 & $-0.2(-)$ \\
\hline Malignant bone tumours & 8 & 0.6 & $13.4(6.7-26.9)$ & $15.6(3.9-27.3)$ \\
\hline Soft-tissue and other extraosseous sarcomas & 9 & 0.5 & $18.5(9.6-35.6)$ & $17.9(5.5-30.3)$ \\
\hline Germ-cell tumours, trophoblastic tumours, and neoplasms of gonads & 5 & 0.9 & $5.6(2.3-13.4)$ & $8.6(-0.6-17.9)$ \\
\hline Other malignant epithelial neoplasms and malignant melanomas & 18 & 1.2 & $15.4(9.7-24.5)$ & $36(17.9-53.0)$ \\
\hline Other and unspecified malignant neoplasms & 0 & 0.2 & 0 & $-0.4(-)$ \\
\hline All categories & 94 & 8.9 & $10.6(8.7-13.1)$ & $\begin{array}{l}179.4(139.3 \\
-219.4)\end{array}$ \\
\hline
\end{tabular}

Abbreviations: AER, absolute excess risk; CI, 95\% confidence interval; CNS, central nervous system; ICCC-3, international classification of childhood cancer, third edition; n, number; SIR, standardised incidence ratio. 
Table 4

Competing risk regression analysis of demographic, cancer, and treatment characteristics and their association with second neoplasm incidence.

\begin{tabular}{|c|c|c|c|c|c|c|}
\hline \multirow[t]{2}{*}{ Characteristics } & \multicolumn{2}{|c|}{ Univariable analysis $^{\mathrm{a}}$} & \multirow{2}{*}{$\begin{array}{l}\mathrm{p}- \\
\text { value }\end{array}$} & \multicolumn{2}{|c|}{ Multivariable analysis $^{\mathrm{a}}$} & \multirow{2}{*}{$\begin{array}{l}\mathrm{p}- \\
\text { value }\end{array}$} \\
\hline & $\begin{array}{l}\text { Subdistribution } \\
\text { HR }\end{array}$ & (CI) & & $\begin{array}{l}\text { Subdistribution } \\
\text { HR }\end{array}$ & (CI) & \\
\hline \multicolumn{7}{|l|}{ Sex } \\
\hline Female & 0.85 & $(0.56-1.28)$ & 0.43 & 0.90 & $(0.59-1.36)$ & 0.60 \\
\hline Age at diagnosis of first primary neoplasm & & & 0.03 & & & 0.02 \\
\hline $0-4$ years & 1 & Ref. & & 1 & Ref. & \\
\hline $5-9$ years & 0.95 & $(0.56-1.62)$ & & 1.03 & $(0.60-1.78)$ & \\
\hline $10-14$ years & 0.63 & $(0.32-1.24)$ & & 0.67 & $(0.34-1.32)$ & \\
\hline $15-20$ years & 1.73 & $(1.06-2.83)$ & & 1.89 & $(1.13-3.16)$ & \\
\hline Diagnosis of first primary neoplasm & & & 0.07 & & & 0.22 \\
\hline $1986-1995$ & 1 & Ref. & & 1 & Ref. & \\
\hline $1996-2005$ & 1.55 & $(0.95-2.53)$ & & 1.41 & $(0.86-2.30)$ & \\
\hline $2006-2015$ & 1.84 & $(1.07-3.17)$ & & 1.56 & $(0.92-2.66)$ & \\
\hline $\begin{array}{l}\text { Diagnostic group of first primary } \\
\text { neoplasm (ICCC-3) }\end{array}$ & & & 0.58 & & & \\
\hline Leukaemias, myeloproliferative and myelodysplastic diseases & 1 & Ref. & & & & \\
\hline Lymphomas and reticuloendothelial neoplasms & 1.11 & $(0.57-2.15)$ & & & & \\
\hline CNS and miscellaneous intracranial and intraspinal neoplasms & 0.84 & $(0.46-1.55)$ & & & & \\
\hline Neuroblastoma and other peripheral nervous cell tumours & 0.98 & $(0.40-2.36)$ & & & & \\
\hline Retinoblastoma & 1.46 & $(0.53-4.02)$ & & & & \\
\hline Renal tumours & 0.76 & $(0.27-2.18)$ & & & & \\
\hline Hepatic tumours & 2.62 & $(0.79-8.66)$ & & & & \\
\hline Malignant bone tumours & 1.09 & $(0.42-2.83)$ & & & & \\
\hline Soft-tissue and other extraosseous sarcomas & 1.05 & $(0.46-2.41)$ & & & & \\
\hline $\begin{array}{l}\text { Germ-cell tumours, trophoblastic tumours, and neoplasms of } \\
\text { gonads }\end{array}$ & 1.83 & $(0.76-4.39)$ & & & & \\
\hline $\begin{array}{l}\text { Other malignant epithelial neoplasms, malignant melanomas, } \\
\text { other and } \\
\text { unspecified malignant neoplasms }\end{array}$ & 0.23 & $(0.03-1.69)$ & & & & \\
\hline Relapse after first primary neoplasm & 1.18 & $(0.73-1.89)$ & 0.50 & & & \\
\hline Cancer predisposition syndromes & 6.58 & $(4.05-10.69)$ & $<0.001$ & 7.83 & $(4.84-12.67)$ & $<0.001$ \\
\hline \multicolumn{7}{|l|}{ Treatment of first primary neoplasm } \\
\hline Chemotherapy & 2.30 & $(1.12-4.70)$ & 0.02 & 2.22 & $(1.08-4.56)$ & 0.03 \\
\hline Radiotherapy & 2.03 & $(1.34-3.06)$ & 0.001 & 1.88 & $(1.23-2.88)$ & 0.003 \\
\hline Haematopoietic stem cell transplantation & 1.99 & $(1.14-3.45)$ & 0.02 & 1.81 & $(1.00-3.25)$ & 0.05 \\
\hline
\end{tabular}

Abbreviations: CI, 95\% confidence interval; HR, hazard ratio; ICCC-3, international classification of childhood cancer, third edition; Ref., reference.

${ }^{\mathrm{a}}$ Univariable and multivariable analysis after multiple imputation by chained equations of missing treatment information (MICE), death as competing risk.

neuroblastoma $(\mathrm{SIR}=16.8,95 \% \mathrm{CI}: 5.2-52.1)$, and other malignant epithelial neoplasms (SIR $=15.4,95 \%$ CI: 9.7-24.5). The AER for any SPN was 179 per 100,000 py, with the highest AERs in CNS neoplasms

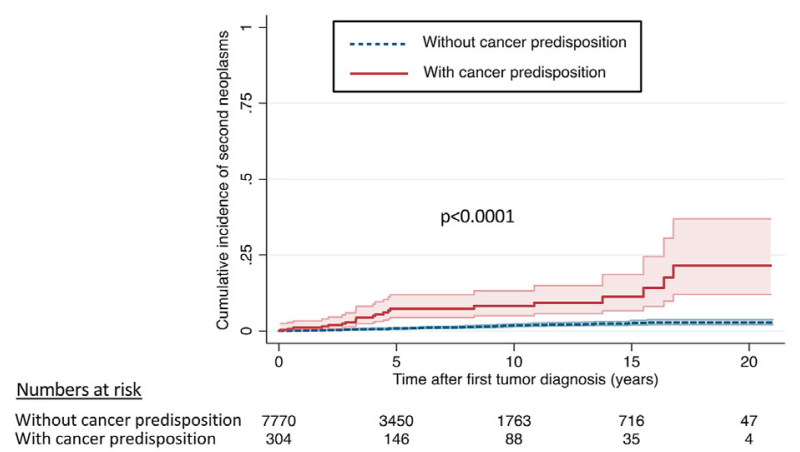

Fig. 1. Cumulative incidence of second primary neoplasms with death as competing risk stratified by diagnosis of a cancer predisposition syndrome.
$(39 / 100,000)$, epithelial neoplasms $(36 / 100,000)$ and leukaemias $(30 / 100,000)$.

\subsection{Predictors for second primary neoplasms}

We found that CPSs, chemotherapy, radiotherapy, HSCT, age at FPN diagnosis, and year of FPN diagnosis were associated with SPNs in the unadjusted competing risk analysis (Table 4). There was no evidence of association of sex, diagnostic group, and relapse with the development of SPNs. In the multivariable analysis, diagnosis of CPSs $(\mathrm{HR}=7.8,95 \% \mathrm{CI}$ : $4.8-12.7)$, age at FPN diagnosis $15-20$ years $(\mathrm{HR}=$ 1.9; $95 \%$ CI: $1.1-3.2$, chemotherapy $(\mathrm{HR}=2.2 ; 95 \%$ CI: $1.1-4.6)$, radiotherapy $(\mathrm{HR}=1.9 ; 95 \% \mathrm{CI}$ : 1.2-2.9), and HSCT (HR = 1.8, CI: 1.0-3.3) remained independent predictors of SPN diagnosis. The HRs were similar in an analysis of those patients with treatment data available (complete case analysis; Supplementary Table A7). The cumulative incidence of SPNs in 
participants with CPSs was $8 \%(\mathrm{CI}: 5-12 \%)$ at 10 years and $23 \%(\mathrm{CI}: 12-41 \%)$ at 20 years after FPN diagnosis, compared with $1.7 \%(\mathrm{CI}: 1.3-2.2)$ at 10 years and $2.7 \%$ (CI: $2.0-3.6 \%$ ) at 20 years in those without CPSs (Fig. 1).

\section{Discussion}

This is the first population-based study to investigate CPSs with demographic, cancer, and treatment characteristics as risk factors for SPNs. This study identified CPSs as the most important risk factor for SPNs in paediatric and adolescent patients. The cumulative incidence of SPNs after 20 years was $23 \%$ in participants with CPSs with an estimate not less than $12 \%$ and as high as $41 \%$ compared with $2.7 \%$ (CI: 2.0-3.6\%) without. Chemotherapy, radiotherapy, HSCT, and older age at FPN diagnosis were also associated with SPNs.

The prevalence of CPSs in our cohort (4\%) was lower than the reported prevalence of CPSs in other studies where comprehensive genetic gene panel testing had been performed on all participants [14,15]. A study from St.Jude Children's Research Hospital assessed 1120 paediatric cancer patients and found $8.5 \%$ affected with CPSs [14], and an international collaborative study in 914 patients identified $7.6 \%$ with CPSs [15]. In contrast to the latter, which identified TP53 mutations associated with $\mathrm{Li}-$ Fraumeni syndrome in $1.5 \%$, we found only three patients or less than $0.1 \%$. In renal tumours, we identified only two patients with WT1 mutations $(0.7 \%)$ where we would expect $2-11 \%$ of Wilms tumour patients be affected [27,28]. This suggests that many known CPSs were not recognised in routine clinical practice in Switzerland. In addition, recently discovered CPSs such as DICERI-associated syndromes were not identified in our cohort [29].

Our results on the standardised incidence ratios and absolute excess risks of SPNs in childhood cancer patients are comparable with the literature. Previous studies have mostly focused on three- to five-year survivors and found SIRs between 5.9 and 11.2 $[2,8,10,11,30,31]$. Differences between studies are partially due to sampling variability and differences of follow-up information, but might also be explained by different calendar periods of FPN diagnosis (with diagnoses in the 1990s reporting a lower cumulative incidence than in the 1970s) [8] and different coding of SPNs [32]. Studies from the U.S., [33], the Nordic countries [12], Ontario (Canada) [4], and Germany [34] have included SPNs within the first years after diagnosis and found SIRs of 6.5-9.9. Similar to our study, high SIRs for CNS neoplasms and bone and soft-tissue sarcomas were also reported by studies from the U.K. and the Netherlands [2,31]. The overall absolute excess risk of
SPNs in our analysis (AER of 179/100,000py) was comparable with previous reports with AERs of about $110-200 / 100,000$ py $[12,31,33]$. AERs in the different SPN groups were similar [4].

We found that cancer predisposition syndromes were the strongest risk factor for early SPNs. The association of CPSs with SPNs has previously been shown but in a selected cohort of 3006 five-year survivors from St.Jude Children's Research Hospital excluding early SMNs. The authors reported an association of CPSs with any SPN in non-irradiated survivors and with selected SPNs (breast cancer and sarcomas) in irradiated survivors [16]. Similarly to our study, radiotherapy and chemotherapy have been associated repeatedly with SPNs [2,7,8,31]. Older age at FPN diagnosis was previously associated with SPNs in a cohort-based study from Israel on 6637 five-year survivors [9] and might reflect particular sensitivity of patients to treatment in this age group or variations in neoplasm subtypes and treatments. We found no evidence of an association of relapse of the FPN with occurrence of SPNs. This was in contrast to a previous case-cohort study from the Nordic countries including 196 SPNs which adjusted for radiotherapy and chemotherapy and found particularly second breast cancers associated with relapse of the FPN [35]. The increased toxicity with FPN relapse treatment might only become relevant after longer follow-up. Similarly, female sex was not associated with SPNs in our analysis, which is likely explained by the lack of breast cancers in our young cohort, which was the main SPN in other studies but occurred usually after 21 years of age [36].

Limitations of our study are that we were not able to assess which patients had undergone genetic counselling, which diagnostic criteria had been used to identify CPSs by treating physicians and consulted geneticists, and whether CPSs had been diagnosed by genetic testing. The investigation of causal genetic mutations in our and similar cohorts will be important to better understand which patients are affected with early SPNs. Another limitation is the crude information on treatment exposures which did not allow us to relate specific treatment agents to SPNs. Finally, because of the limited number of events in our population, confidence intervals and estimation of incidence ratios and excess risks are wide.

A strength of our study is the inclusion of SPNs since diagnosis of FPN which provides a complete assessment of SPNs in the paediatric and adolescent age range. These patients were assessed for SPNs in only a few previous studies. $22 \%$ of patients with early SPNs being diagnosed with CPSs exceed what we would expect for the childhood cancer population of about $8 \%[14,15]$. Only one patient has been diagnosed with a CPS after SPN diagnosis which speaks against ascertainment bias. This also suggests that the occurrence of an SPN has not led to intensified search for CPSs. Then, because of the 
continuous collection of information into the SCCR with yearly follow-up information and medical reports, we were able to assemble detailed clinical data from the initial cancer treatment period and from follow-up appointments. Finally, our study is based on a nationwide, population-based cancer registry, so that our results are representative for all Switzerland and childhood cancer in countries with access to modern workup and treatment modalities.

Identification of patients at increased risk of SPNs is imperative to tailor cancer surveillance. The strong association of CPSs with SPNs in our study and occurrence of SPNs within the first years after FPNs in some patients highlight the importance of identifying CPSs in childhood cancer patients. Adapted cancer surveillance protocols for specific CPSs include multimodal screening methods [37-39] and yield survival advantages $[40,41]$. This is relevant for newly diagnosed patients but also those who have been cured of their primary disease, as the identification of CPSs may have been missed during initial workup and treatment. Algorithms [42] and tools available online and as a smartphone application [43] have been developed that help identify childhood cancer patients at increased risk for CPSs. Their ease of use in a routine diagnostic setting will help clinicians select patients who warrant genetic counselling which might improve recognition of CPSs. Appropriate surveillance of patients with CPSs is important and might improve early detection of SPNs and ultimately long-term survival.

\section{Role of funding source}

The funding sources had no role in the design of this study, its execution, analyses, interpretation of the data, or decision to submit results. The funding sources of the Swiss Childhood Cancer Registry support the daily running of the registry and have not had any role in the design, conduct, interpretation, or publication of the Swiss Childhood Cancer Registry itself as well as the related research projects.

\section{Author contribution statement}

Nicolas Waespe: conceptualisation, methodology, data preparation and curation, statistical analysis, writing all stages, visualisation; Fabien Belle: writing reviewing and editing; Shelagh Redmond: data collection, preparation and curation, writing - reviewing and editing; Christina Schindera: writing - reviewing and editing; Ben Spycher: statistical analysis, writing reviewing and editing; Claudia E. Kuehni: supervision, conceptualisation, methodology, statistical analysis, writing - reviewing and editing; Marc Ansari and Jochen Roessler: writing - reviewing and editing.

\section{Conflict of interest statement}

The authors declare that they have no known competing financial interests or personal relationships that could have appeared to influence the work reported in this paper.

\section{Acknowledgements}

The authors thank all childhood cancer patients and families for participating in this study. They thank the study team at the Institute of Social and Preventive Medicine, University of Bern (Luzius Mader, Maria Otth, Sven Strebel, Jana Remlinger, Grit Sommer), the data managers of the Swiss Paediatric Oncology Group (Claudia Althaus, Nadine Assbichler, Pamela Balestra, Heike Baumeler, Nadine Beusch, Sarah Blanc, Pierluigi Brazzola, Susann Drerup, Janine Garibay, Franziska Hochreutener, Monika Imbach, Friedgard Julmy, Eléna Lemmel, Rodolfo Lo Piccolo, Heike Markiewicz, Veneranda Mattiello, Annette Reinberg, Renate Siegenthaler, Astrid Schiltknecht, Beate Schwenke, and Verena Stahel) and the data managers and administrative staff at the Institute of Social and Preventive Medicine, University of Bern (Meltem Altun, Erika Brantschen, Katharina Flandera, Elisabeth Kiraly, Verena Pfeiffer, Julia Ruppel, Ursina Roder, and Nadine Lötscher). We thank the Federal Office of Public Health (FOPH) and the National Institute of Cancer Epidemiology and Registration (www.nicer.org) for providing information on cancer incidence rates in Switzerland.

This study was supported by the CANSEARCH Foundation, the Swiss National Science Foundation (31BL30_185396), Swiss Cancer Research and the Swiss Cancer League (KLS-3886-02-2016 and KLS/KFS-482501-2019, KFS-4722-02-2019), "Stiftung für krebskranke Kinder Regio Basiliensis." The work of the Swiss Childhood Cancer Registry is supported by the Swiss Paediatric Oncology Group (www.spog.ch), Schweizerische Konferenz der kantonalen Gesundheitsdirektorinnen und -direktoren (www.gdk-cds.ch), Swiss Cancer Research (www.krebsforschung.ch), and Kinderkrebshilfe Schweiz (www.kinderkrebshilfe.ch).

\section{Appendix A. Supplementary data}

Supplementary data to this article can be found online at https://doi.org/10.1016/j.ejca.2020.11.042.

\section{References}

[1] Schindler M, Spycher BD, Ammann RA, Ansari M, Michel G, Kuehni CE, et al. Cause-specific long-term mortality in survivors of childhood cancer in Switzerland: a population-based study. Int J Canc 2016;139:322-33. https://doi.org/10.1002/ijc.30080. 
[2] Jenkinson HC, Hawkins MM, Stiller CA, Winter DL, Marsden HB, Stevens MCG. Long-term population-based risks of second malignant neoplasms after childhood cancer in Britain. Br J Canc 2004;91:1905-10. https://doi.org/10.1038/sj.bjc.6602226.

[3] Choi DK, Helenowski I, Hijiya N. Secondary malignancies in pediatric cancer survivors: perspectives and review of the literature. Int J Canc 2014;135:1764-73. https://doi.org/10.1002/ijc.28991.

[4] Pole JD, Gu LY, Kirsh V, Greenberg ML, Nathan PC. Subsequent malignant neoplasms in a population-based cohort of pediatric cancer patients: a focus on the first 5 years. Cancer Epidemiol Biomarkers Prev 2015;24:1585-92. https: //doi.org/10.1158/1055-9965.EPI-15-0360.

[5] Bagnasco F, Caruso S, Andreano A, Valsecchi MG, Jankovic M, Biondi A, et al. Late mortality and causes of death among 5-year survivors of childhood cancer diagnosed in the period 1960-1999 and registered in the Italian Off-Therapy Registry. Eur J Canc 2019;110:86-97. https://doi.org/10.1016/j.ejca.2018.12.021.

[6] Neglia JP, Friedman DL, Yasui Y, Mertens AC, Hammond S, Stovall $\mathrm{M}$, et al. Second malignant neoplasms in five-year survivors of childhood cancer: childhood cancer survivor study. J Natl Cancer Inst 2001;93:618-29. https://doi.org/10. 1093/jnci/93.8.618.

[7] Friedman DL, Whitton J, Leisenring W, Mertens AC, Hammond S, Stovall M, et al. Subsequent neoplasms in 5-year survivors of childhood cancer: the childhood cancer survivor study. J Natl Cancer Inst 2010;102:1083-95. https: //doi.org/10.1093/jnci/djq238.

[8] Turcotte LM, Liu Q, Yasui Y, Arnold MA, Hammond S, Howell RM, et al. Temporal trends in treatment and subsequent neoplasm risk among 5-year survivors of childhood cancer, 19702015. J Am Med Assoc 2017;317:814-24. https://doi.org/10.1001/ jama.2017.0693.

[9] Hayek S, Dichtiar R, Shohat T, Silverman B, Ifrah A, Boker LK. Risk of second primary neoplasm and mortality in childhood cancer survivors based on a national registry database. Cancer Epidemiology 2018;57:127-33. https://doi.org/10.1016/j.canep. 2018.10.012.

[10] Reulen RC, Frobisher C, Winter DL, Kelly J, Lancashire ER, Stiller CA, et al. Long-term risks of subsequent primary neoplasms among survivors of childhood cancer. J Am Med Assoc 2011;305:2311-9. https://doi.org/10.1001/jama.2011.747.

[11] Turcotte LM, Neglia JP, Reulen RC, Ronckers CM, van Leeuwen FE, Morton LM, et al. Risk, risk factors, and surveillance of subsequent malignant neoplasms in survivors of childhood cancer: a review. J Clin Oncol 2018;36:2145-52. https: //doi.org/10.1200/JCO.2017.76.7764.

[12] Olsen JH, Möller T, Anderson H, Langmark F, Sankila R, Tryggvadóttír L, et al. Lifelong cancer incidence in 47697 patients treated for childhood cancer in the nordic countries. J Natl Cancer Inst 2009;101:806-13. https://doi.org/10.1093/jnci/djp104.

[13] Ju HY, Moon E-K, Lim J, Park BK, Shin HY, Won Y-J, et al. Second malignant neoplasms after childhood cancer: a nationwide population-based study in Korea. PloS One 2018;13:e0207243. https://doi.org/10.1371/journal.pone.0207243.

[14] Zhang J, Walsh MF, Wu G, Edmonson MN, Gruber TA, Easton $\mathrm{J}$, et al. Germline mutations in predisposition genes in pediatric cancer. N Engl J Med 2015;373:2336-46. https: //doi.org/10.1056/NEJMoa1508054.

[15] Gröbner SN, Worst BC, Weischenfeldt J, Buchhalter I, Kleinheinz K, Rudneva VA, et al. The landscape of genomic alterations across childhood cancers. Nature 2018;555:321-7. https: //doi.org/10.1038/nature25480.

[16] Wang Z, Wilson CL, Easton J, Thrasher A, Mulder H, Liu Q, et al. Genetic risk for subsequent neoplasms among long-term survivors of childhood cancer. J Clin Orthod 2018;77:8589. https://doi.org/10.1200/JCO.2018.77.8589.

[17] Malkin D, Nichols KE, Zelley K, Schiffman JD. Predisposition to pediatric and hematologic cancers: a moving target. Am Soc Clin
Oncol Educ Book 2014:e44-55. https: //doi.org/10.14694/EdBook_AM.2014.34.e44.

[18] Michel G, von der Weid NX, Zwahlen M, Adam M, Rebholz CE, Kuehni CE, et al. The Swiss Childhood Cancer Registry: rationale, organisation and results for the years 2001-2005. Swiss Med Wkly 2007;137:502-9. https://doi.org/10.2007/35/smw-11875.

[19] Schindler M, Mitter V, Bergstraesser E, Gumy-Pause F, Michel G, Kuehni CE, et al. Death certificate notifications in the Swiss Childhood Cancer Registry: assessing completeness and registration procedures. Swiss Med Wkly 2015;145:w14225. https: //doi.org/10.4414/smw.2015.14225.

[20] Steliarova-Foucher E, Stiller C, Lacour B, Kaatsch P. International classification of childhood cancer. third edition Cancer 2005;103:1457-67. https://doi.org/10.1002/cncr.20910.

[21] Rahman N. Realizing the promise of cancer predisposition genes. Nature 2014;505:302-8. https://doi.org/10.1038/nature12981.

[22] Kuehni CE, Rueegg CS, Michel G, Rebholz CE, Strippoli M-PF, Niggli FK, et al. Cohort profile: the Swiss childhood cancer survivor study. Int $\mathbf{J}$ Epidemiol 2012;41:1553-64. https: //doi.org/10.1093/ije/dyr142.

[23] Working Group Report. International rules for multiple primary cancers (ICD-0 third edition). Eur J Canc Prev 2005;14:307-8. https://doi.org/10.1097/00008469-200508000-00002.

[24] Sommer G, Schindler M, Redmond S, Pfeiffer V, Konstantinoudis G, Ammann RA, et al. Temporal trends in incidence of childhood cancer in Switzerland, 1985-2014. Cancer Epidemiology 2019;61:157-64. https://doi.org/10.1016/j.canep. 2019.06.002.

[25] Federal Statistical Office. Cancer Incidence in Switzerland n.d. https://www.bfs.admin.ch/bfs/en/home/statistiken/gesundheit/ gesundheitszustand/krankheiten/krebs.html. [Accessed 17 September 2019].

[26] Fine JP, Gray RJ. A proportional hazards model for the subdistribution of a competing risk. J Am Stat Assoc 1999;94: 496-509. https://doi.org/10.1080/01621459.1999.10474144.

[27] Little SE, Hanks SP, King-Underwood L, Jones C, Rapley EA, Rahman N, et al. Frequency and heritability of WT1 mutations in nonsyndromic Wilms' tumor patients: a UK Children's cancer study group study. J Clin Oncol 2004;22:4140-6. https: //doi.org/10.1200/JCO.2004.02.136.

[28] Segers H, Kersseboom R, Alders M, Pieters R, Wagner A, van den Heuvel-Eibrink MM. Frequency of WT1 and $11 \mathrm{p} 15$ constitutional aberrations and phenotypic correlation in childhood Wilms tumour patients. Eur J Canc 2012;48:3249-56. https: //doi.org/10.1016/j.ejca.2012.06.008.

[29] Hill DA, Ivanovich J, Priest JR, Gurnett CA, Dehner LP, Desruisseau D, et al. DICER1 mutations in familial pleuropulmonary blastoma. Science (New York, NY) 2009;325:965. https://doi.org/10.1126/science.1174334.

[30] Cardous-Ubbink MC, Heinen RC, Bakker PJM, van den Berg H, Oldenburger F, Caron HN, et al. Risk of second malignancies in long-term survivors of childhood cancer. Eur J Canc 2007;43: 351-62. https://doi.org/10.1016/j.ejca.2006.10.004.

[31] Teepen JC, van Leeuwen FE, Tissing WJ, van Dulmen-den Broeder E, van den Heuvel-Eibrink MM, van der Pal HJ, et al. Long-term risk of subsequent malignant neoplasms after treatment of childhood cancer in the DCOG LATER study cohort: role of chemotherapy. J Clin Oncol 2017;71:2288-98. https: //doi.org/10.1200/JCO.2016.71.6902.

[32] Weir HK, Johnson CJ, Ward KC, Coleman MP. The effect of multiple primary rules on cancer incidence rates and trends. Cancer Causes Control 2016;27:377-90. https: //doi.org/10.1007/s10552-016-0714-9.

[33] Inskip PD, Curtis RE. New malignancies following childhood cancer in the United States, 1973-2002. Int J Canc 2007;121: 2233-40. https://doi.org/10.1002/ijc.22827.

[34] Scholz-Kreisel P, Kaatsch P, Spix C, Schmidberger H, Marron M, Grabow D, et al. Second malignancies following childhood cancer 
treatment in Germany from 1980 to 2014. Dtsch Arztebl Int 2018; 115:385-92. https://doi.org/10.3238/arztebl.2018.0385.

[35] Svahn-Tapper G, Garwicz S, Anderson H, Shamsaldin A, Vathaire FD, Olsen $\mathrm{JH}$, et al. Radiation dose and relapse are predictors for development of second malignant solid tumors after cancer in childhood and adolescence: a population-based casecontrol study in the five Nordic countries. Acta Oncologica 2006; 45:438-48. https://doi.org/10.1080/02841860600658633.

[36] Moskowitz CS, Chou JF, Wolden SL, Bernstein JL, Malhotra J, Friedman DN, et al. Breast cancer after chest radiation therapy for childhood cancer. J Clin Oncol 2014;32:2217-23. https: //doi.org/10.1200/JCO.2013.54.4601.

[37] Walsh MF, Chang VY, Kohlmann WK, Scott HS, Cunniff C, Bourdeaut $\mathrm{F}$, et al. Recommendations for childhood cancer screening and surveillance in DNA repair disorders. Clin Canc Res 2017;23:e23-31. https://doi.org/10.1158/1078-0432.CCR-170465.

[38] Villani A, Greer M-LC, Kalish JM, Nakagawara A, Nathanson KL, Pajtler KW, et al. Recommendations for cancer surveillance in individuals with RASopathies and other rare genetic conditions with increased cancer risk. Clin Canc Res 2017; 23:e83-90. https://doi.org/10.1158/1078-0432.CCR-17-0631.

[39] Brioude F, Kalish JM, Mussa A, Foster AC, Bliek J, Ferrero GB, et al. Expert consensus document: clinical and molecular diagnosis, screening and management of Beckwith-Wiedemann syndrome: an international consensus statement. Nat Rev Endocrinol 2018;14:229-49. https://doi.org/10.1038/nrendo.2017.166.

[40] Villani A, Tabori U, Schiffman J, Shlien A, Beyene J, Druker H, et al. Biochemical and imaging surveillance in germline TP53 mutation carriers with Li-Fraumeni syndrome: a prospective observational study. Lancet Oncol 2011;12:559-67. https: //doi.org/10.1016/S1470-2045(11)70119-X.

[41] Villani A, Shore A, Wasserman JD, Stephens D, Kim RH, Druker $\mathrm{H}$, et al. Biochemical and imaging surveillance in germline TP53 mutation carriers with Li-Fraumeni syndrome: 11 year follow-up of a prospective observational study. Lancet Oncol 2016;17:1295-305. https://doi.org/10.1016/S1470-2045(16)302492.

[42] Jongmans MCJ, Loeffen JLCM, Waanders E, Hoogerbrugge PM, Ligtenberg MJL, Kuiper RP, et al. Recognition of genetic predisposition in pediatric cancer patients: an easy-to-use selection tool. Eur J Med Genet 2016;59:116-25. https: //doi.org/10.1016/j.ejmg.2016.01.008.

[43] Goudie C, Coltin H, Witkowski L, Mourad S, Malkin D, Foulkes WD. The McGill Interactive Pediatric OncoGenetic Guidelines: an approach to identifying pediatric oncology patients most likely to benefit from a genetic evaluation. Pediatr Blood Cancer 2017;64:e26441. https://doi.org/10.1002/pbc.26441. 